Published in final edited form as:

Med Chem Res. 2016 August ; 25(8): 1515-1523. doi:10.1007/s00044-016-1607-x.

\title{
Anticancer properties of baicalein: a review
}

\author{
Ying Gao a,b Shane A. Snydera, Jaclyn N. Smith ${ }^{a}$, and Yi Charlie Chen ${ }^{a}$, \\ ${ }^{a}$ College of Science, Technology \& Mathematics, Alderson Broaddus University, Philippi, WV \\ 26416, USA \\ bepartment of Tea Science, Zhejiang University, Hangzhou 310058, China
}

\begin{abstract}
The constituents of many traditional Chinese herbal remedies are currently at the forefront of modern cancer research. Baicalein, a bioactive flavone widely used in nutraceuticals and pharmaceuticals, has shown great potential in the treatment and prevention of cancer without causing severe side effects. Baicalein induces cancer cell apoptosis and cause cell cycle arrest. It shows inhibitory effects on angiogenesis, metastasis and inflammation, all of which are necessary for the promotion and progression of cancer. This review presents an overview of the anti-cancer effects and mechanisms of baicalein. In addition, the bioavailability of baicalein and approaches to improve it are summarized. Treatments of baicalein in combination with other anti-cancer agents are also mentioned.
\end{abstract}

\section{Keywords}

Baicalein; Apoptosis; Angiogenesis; Metastasis; Bioavailability

\section{Introduction}

Herbal plants have long been utilized to prevent and treat diseases. Nowadays, many people still rely on herbal nutraceuticals for their primary health care. More than $50 \%$ of the drugs currently in clinical application are of natural product origin (Sithranga Boopathy and Kathiresan 2010). Scutellaria baicalensis Georgi is a species of flowering plant in the Lamiaceae family. The dried root of Scutellaria baicalensis Georgi is widely and historically used in Traditional Chinese Medicine (Li-Weber 2009). Flavonoids, a class of secondary metabolites commonly found in plants, are one of the most important bioactive components in the root of Scutellaria baicalensis Georgi. Epidemiological studies have found a significant correlation between the dietary intake of flavonoids and a reduced risk of cancer, inflammation and heart disease (Li-Weber 2009). Over 50 flavonoids have been isolated from the root of Scutellaria baicalensis Georgi, including baicalein, baicalin, wogonin, norwogonin, oroxylin A and $\beta$-sitosterol. Baicalein (5,6,7-trihydroxyflavone, Fig. 1), one of four major flavonoids existed in the root of Scutellaria baicalensis Georgi (Kim et al. 2013), is an important active constituent responsible for the physiological activity of Scutellaria baicalensis Georgi (Mehendale et al. 2007). Previous researches have shown that baicalein

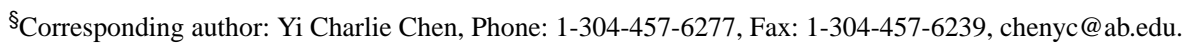


exerts numerous biological activities, such as anti-cancer, anti-inflammation, anticardiovascular diseases, anti-bacterial or viral infection, and anti-neurodegenerative diseases. Studies have demonstrated that baicalein suppresses cancer cell proliferation, induces apoptosis and cell cycle arrest in human breast, prostate, hepatocellular, myeloma and T24 bladder cancer cells (Chen et al. 2014b; Li et al. 2013a). Baicalein inhibits migration and invasion of human breast cancer cells, hepatoma cells and skin cancer cells (Chiu et al. 2011; Wang et al. 2010b; Wu et al. 2011). Like most flavonoids, baicalein is hydroxylated at the C-5 position, which is vital for its extensive pharmacological effects (Moon et al. 2006). This review focuses on various anti-cancer effects and mechanisms of baicalein, as well as the future use of baicalein in modern medicine.

\section{Extraction}

To isolate baicalein from over 781 compounds contained in extracts of Scutellaria baicalensis Georgi, various extraction methods have been implemented, such as high-speed counter-current chromatography, dynamic microwave-assisted extraction, and on-line continuous flow ultrasonic extraction. There is much debate as to which extraction method is most efficient for medical use ( $\mathrm{Li}$ et al. 2011b). Traditional extraction method and supercritical fluid extraction (SFE) method are two of the widely-used methods in extracting baicalein.

A traditional procedure used for baicalein extraction is to ground the dried roots of Scutellaria baicalensis Georgi to fine powder, extract with $70 \%$ ethanol for two hours, and collect the filtrate. Repeat the extraction and filtration steps a few more times (Lin et al. 2013). The filtrate was then vacuum lyophilized and examined using high performance liquid chromatography (HPLC).

SFE is another commonly used extraction method for baicalein because of its quick yields and cost efficiency. Methanol and ethanol are generally used as the solvent in SFE as they are low-toxic and yield the most efficient results ( $\mathrm{Li}$ et al. 2011b). The solvent and ground Scutellaria baicalensis Georgi is actively mixed for approximately 24 hours at room temperature followed by repeated extraction and removal of the solvent. Then, the extracts are recrystallized. The purity of the extracted flavonoids are tested using the HPLC method (Chen and Chen 2013).

\section{Effect on apoptosis}

Apoptosis is an ordered and orchestrated cellular process that occurs in physiological and pathological conditions (Wong 2011). The morphological changes of apoptosis include blebbing, cell shrinkage, nuclear fragmentation, chromatin condensation, and chromosomal DNA fragmentation. Unlike necrosis, apoptosis produces apoptotic bodies that phagocytic cells are able to engulf and quickly remove before the contents of the cell can spill out onto surrounding cells and cause damage. Resisting apoptosis is a key process in cancer development and progression. Cancer cells that avoid apoptosis continue to proliferate uncontrollably, which results in an increased tumor mass. Therefore, apoptosis is a popular target of many treatment strategies (Kasibhatla and Tseng 2003). Apoptosis is 
predominantly initiated through mitochondria-mediated (intrinsic) and receptor-mediated (extrinsic) pathways (Li-Weber 2009). The intrinsic apoptotic pathway is characterized by permeabilisation of the mitochondria, release of Cytochrome $\mathrm{c}$ into the cytoplasm and activation of the Caspase cascade through Caspase-9. The extrinsic apoptotic pathway is activated by the binding of membrane death receptors with their ligands, such as the tumor necrosis factor-related apoptosis-inducing ligand (TRAIL), tumor necrosis factor-a (TNFa), and CD95L, leading to initiation of the Caspase cascade through Caspase-8. In some cases, extrinsic and intrinsic pathways can crosstalk and be linked together.

Baicalein has shown potent apoptosis-inducing properties in various types of cancer. It initiates apoptosis through both the mitochondria-mediated (intrinsic) and receptor-mediated (extrinsic) pathways (Li-Weber 2009). The mechanisms are diverse.

One of the mechanisms is that baicalein directly modulates the components of intrinsic and extrinsic apoptotic pathway. Bcl-2 family comprises a group of structurally related proteins that play a fundamental role in the intrinsic apoptotic pathway. Bcl-2 family protein can be either pro-apoptotic (for example, Bax, Bad, Bak) or anti-apoptotic (for example, Bcl-2, Bcl$\mathrm{xL}, \mathrm{Mcl}-1$, and $\mathrm{Bcl}-\mathrm{w})$. The ratio of pro- to anti-apoptotic Bcl-2 family proteins determines cell fate. In SCC-4 human tongue cancer cells, baicalein successfully induced apoptosis by elevating levels of pro-apoptotic agents (Bax) and lowering the level of anti-apoptotic protein Bcl-2 (Lin et al. 2007). The increasing ratio of pro- to anti-apoptotic Bcl-2 family proteins caused release of Cytochrome $\mathrm{c}$ and other apoptogenic proteins from the mitochondrial membrane to cytosol, lead to activation of Caspase cascade, and finally initiated apoptosis in the target cells (Zhang et al. 2013b). Death receptor 5 (DR5) and other TRAIL receptors, components of the extrinsic apoptotic pathway, were significantly increased at protein and mRNA levels by baicalein in cancer cells in comparison with normal cells, showing great promise in serving as a therapeutic agent (Taniguchi et al. 2008).

Another mechanism is that baicalein regulates the apoptotic pathway via radical oxygen species (ROS). ROS play an important role in a variety of normal biochemical functions and abnormal pathological processes (Pelicano et al. 2004). When overexpressed, ROS can create oxidative stress and eventually cause mitochondrial dysfunction (Lee et al. 2011). Due to this, ROS production is a mechanism shared by all non-surgical therapeutic approaches for cancer, including chemotherapy, radiotherapy and photodynamic therapy (Wang and Yi 2008). Like other flavonoids, baicalein can be either anti-oxidant or pro-oxidant, depending on its metabolism and concentration. It is reported that baicalein generated ROS, subsequently caused endoplasmic reticulum (ER) stress, activated $\mathrm{Ca}^{2+}$-dependent mitochondrial death pathway, finally triggered apoptosis (Lee et al. 2008; Lin et al. 2007). Baicalein also enhanced apoptosis via ROS-mediated Bcl-2/adenovirus E1B $19 \mathrm{kDa}$ proteininteracting protein 3 (BNIP3) expression (Ye et al. 2015). Besides, baicalein-induced ROS generation up-regulated DR5 expression and then activated the extrinsic apoptotic pathway in human prostate cancer cells (Taniguchi et al. 2008).

Affecting upstream signal pathways of the apoptotic pathways is also an important mechanism. Mitogen-activated protein kinases (MAPKs) are a highly conserved family of serine/threonine protein kinases, mainly including the extracellular signal-regulated kinase 1 
and 2 (ERK 1/2), the c-Jun N-terminal kinases 1-3 (JNK 1-3)/ stress activated protein kinases and p38 isoforms. MAPK pathways involve in fundamental cellular processes such as proliferation, apoptosis, and survival. It is activated when an extracellular messenger or ligand binds to a membrane-bound receptor, which in turn activates RAS-GTP and triggers a phosphorylation cascade. The MAPK pathway finally reaches an activator protein in the nucleus which can generate the expression of growth factors, cyclins, and/or, cytokines (Gao et al. 2010). The p38 MAPK pathway is often targeted by anti-cancer drugs as it induces and mediates apoptosis through the activation of different Caspases (Moon et al. 2006).

Baicalein enhanced phosphorylation of p38 MAPK, diminished protein level of survivin, a member of the inhibitor of apoptosis (IAP) gene family, in bladder, lung, and breast cancer cells (Moon et al. 2006). Baicalein, together with baicalin, increased apoptosis by activating Caspases-3 and Caspase-9, down-regulating Bcl-2 and up-regulating Bax or p53 through the ERK/p38 MAPK pathway (Zhou et al. 2009).

p53 is a tumour suppressor protein that regulates the expression of a wide variety of genes involved in apoptosis, growth inhibition and cell cycle arrest. Baicalein induced apoptosis through up-regulating p53 in A549, SK-LU-1 and SK-MES-1 human lung cancer cell lines. In HT-29 colon cancer cells, baicalein triggered apoptosis via Akt activation in a p53dependent manner (Kim et al. 2012).

The phosphoinositide 3-kinase(PI3K)/Akt pathway is an intracellular signaling pathway which plays a critical regulatory role in diverse cellular processes, such as angiogenesis, metabolism, growth, proliferation, and survival (Hemmings and Restuccia 2012). Baicalein can slow down cancer development by inhibiting the function of four different isoforms of PI3K (Kong et al. 2011). Once treated with baicalein, EC-109 esophageal squamous carcinoma cells yielded drastically decreased expression of nuclear transcription factor kappa-B (NF- $\kappa \mathrm{B})$ and phosphorylation of Akt, mTOR and $\mathrm{I} \kappa \mathrm{B}$ in a time-dependent manner (Zhang et al. 2013a). Through the decreased expression of NF- $\kappa \mathrm{B}$, a transcription factor that serves to promote cell survival and impair apoptotic activity, baicalein successfully overcame the $\mathrm{PI}_{3} \mathrm{~K} /$ Akt pathway and induced apoptosis in cancerous cells (Zhou et al. 2009).

Platelet-type 12-Lipoxygenase (12-LOX) is found to be involved in the progression of human cancers and the inhibitor of 12-LOX offers a target for the prevention of cancer (Leung et al. 2007). Baicalein is known as a 12-LOX inhibitor. By inactivating 12-LOX, baicalein reduced the levels of anti-apoptotic proteins Bcl-2 and Mcl-1, and increased the levels of the pro-apoptotic protein Bax (Tong et al. 2002a; Tong et al. 2002b). It markedly induced the release of Cytochrome $\mathrm{c}$ from mitochondria into the cytosol and activated Caspase-9, Caspase-7, and Caspase-3, concomitant with cleavage of the Caspase-3 substrate poly(ADP-ribose) polymerase (Tong et al. 2002a; Tong et al. 2002b), finally caused apoptosis.

\section{Effect on cell cycle}

Cell cycle is the series of events that take place in a cell leading to its division and duplication. In actively dividing eukaryote cells, cell cycle is composed of four stages: Gap 1 
phase (G1), Synthesis phase (S), Gap 2 phase (G2) and Mitosis phase (M). There are different checkpoints all along the cell cycle to verify whether the processes at each phase of the cell cycle have been accurately completed before progression into the next phase. The cell cycle checkpoints are made up of cyclin-dependent kinases (CDKs), CDK subunits (Cyclins), and CDK inhibitors (CDKIs) as well as phosphorylated retinoblastoma protein (p$\mathrm{Rb}$ ) (Cheng et al. 2012). When cells fail to overcome cell cycle checkpoints, cell cycle arrest is triggered. G1 arrest may slow growth and induce cell death. G2/M arrest may increase the cytotoxicity of chemotherapy and be associated with enhanced apoptosis (Tyagi et al. 2002). Cancer represents a dysregulation of cell cycle, resulting in uncontrolled cell proliferation. Inducing cell cycle arrest can help to inhibit cancer. Baicalein causes cell cycle arrest during different phases based on types of cancer (Lee et al. 2005). Baicalein induces G1/S arrest due to increased Cyclin E expression, a major factor in the regulation of the G1/S checkpoint of the cell cycle, accompanied by reduced levels of Cdk 4 and Cyclin D1 in human lung squamous carcinoma (CH27) cells (Lee et al. 2005) and osteosarcoma cells (Lin et al. 2007). In prostate cancer cells, baicalein induced G0/G1 arrest via decreasing cyclin D1, cyclin D3 and phosphorylated retinoblastoma (pRB) protein (Pidgeon et al. 2002). In Hep G2 and Hep J2 hepatoma cells, baicalein treatment dramatically caused S-phase arrest (Chen et al. 2000). The underlying mechanisms include DNA damage in the early stages, inhibition of growth stimulating factors, and the induction of CDK inhibitors such as p21 or p27 (Chen et al. 2000). In bladder cancer cells, baicalein induced G2/M arrest by affecting cyclin B1 and phospho-Cdc2 (Thr161), two vital proteins for the initation of mitosis (Chao et al. 2007). In addition, baicalein along with other extracts halted the cell cycle during the S and G2/Mphases in MCF-7 human breast cancer cells by suppressing $17 \beta$-estradiol-induced transactivation of estrogen receptor a (Po et al. 2002; Wang et al. 2010a).

\section{Effect on angiogenesis}

Angiogenesis is a fundamental step in the transition of tumors from a benign state to a malignant one. Angiogenesis is a multi-step physiological neovascularization produced through the development of new capillary blood vessels from previously established vessels, carried out through factors such as the vascular endothelial growth factor (VEGF) (Liu et al. 2003). Neovascularization is required for the growth of solid tumors and can be controlled by the pro-oncogene c-Myc, which ensures VEGF expression through HIF-1 (Chen et al. 2013a; Liu et al. 2003).

Baicalein displays repressive effect on angiogenesis. When cultured with conditioned medium from baicalein and baicalin-treated cancer cells, the average number and length of sprouts formed by the endothelial cell aggregates was significantly decreased in a dosedependent manner (Miocinovic et al. 2005). It can partially be attributed to the baicaleininduced reduction of angiogenic related protein. In ovarian cancer cells, baicalein effectively lowered the protein level of VEGF, c-Myc, HIF- $a$, and NFkB (Chen et al. 2013a). In BV2 microglia, baicalein suppressed expression of hypoxia-induced HIF-1 $a$ and hypoxia responsive genes, including inducible nitric oxide synthase (iNOS), COX-2, and VEGF, by inhibiting ROS and PI3K/Akt pathway (Hwang et al. 2008). In addtion, baicalein influenced phosphorylation of VEGF receptor 2 and ERK in human umbilical vein endothelial cells (HUVECs), which lead to the failure of new blood vessel formation (Ling et al. 2011). 
Interestingly, baicalein can be utilized as a pro-angiogenic agent in certain cases (Cho et al. 2008). Baicalein was reavealed to promote HIF-1 genes and the growth of new blood vessels by reducing ubiquitination and asparaginyl hydroxylation of HIF-1a (Cho et al. 2008). It is possible that baicalein could work as both a pro-angiogenic and anti-angiogenic agent depending on the dosage and cell types (Cho et al. 2008).

\section{Effect on metastasis}

Metastasis is the process by which cancer cells spread from the place where it first started to other parts of the body. It is a pivotal factor for poor prognosis. In fact, for many cancers it is the metastatic recurrence, not the primary tumor that ultimately proves to be fatal.

Metastasis consists of multiple steps which are regulated by a series of proteases, including matrix metalloproteinases (MMPs), cathepsins and plasminogen activator (PA), all of which damage the extracellular matrix (ECM) (Chen et al. 2013b), allowing cancer cells break away from the primary tumor tissue and migrate to other tissues.

Baicalein inhibits invasion and migration in various cancer cells, mainly via reducing the expression and proteinase activity of matrix metalloproteinases (Chandrashekar et al. 2012; Kim et al. 2013; Wu et al. 2013; Zhang et al. 2013b), and/or increasing the expression of tissue inhibitors of metalloproteinase (TIMPs) (Chen et al. 2013b; Zhang et al. 2014b). MAPK pathway is a crucial target of baicalein (Chen et al. 2013b; Wang et al. 2010b; Yan et al. 2015; Zhang et al. 2014b). By diminishing phosphorylated levels of ERK, p38 and JNK, baicalein significantly inhibited the expression and secretion of MMP-2/9 in MDA-MB-231 cells (Wang et al. 2010b). Likewise, baicalein reduced expression and proteinase activity of MMP-2/9 and increased expression of TIMP-1/2 by impairing phosphorylation of $\mathrm{p} 38$ in glioma cells (Zhang et al. 2014b). In hepatocellular carcinoma cells, baicalein inhibited the phosphorylation of MEK1 and ERK1/2, leading to decreased expression and proteinase activity of MMP-2/9 and urokinase-type plasminogen activator (u-PA), as well as increased expression of TIMP-1 and TIMP-2 (Chen et al. 2013b). Although playing an important role in regulating metastasis in many cancer cells, MAPK pathway is not the only target of baicalein. Baicalein suppressed the TGF- $\beta / S m a d 4$ signaling pathway and reduced the expression of the metastasis-associated $\mathrm{N}$-cadherin, vimentin, ZEB1 and ZEB2 in gastric cancer cells (Chen et al. 2014a). Morever, baicalein inhibited E2-induced migration, adhesion and invasion by interfering with $17 \beta$-estradiol (E2)-induced novel $\mathrm{G}$ proteincoupled estrogen receptor (GPR30)-related signaling (Shang et al. 2015). Ezrin (Tang et al. 2015; Wu et al. 2011) and zinc finger protein X-linked (ZFX) (Liu et al. 2015) were also involved in the anti-metastatic machanisms of baicalein.

\section{Effect on inflammation}

Inflammation is part of the biological response of vascular tissues to harmful stimuli, such as pathogens, damaged cells, or irritants. Inflammation can be classified as acute and chronic. Chronic inflammation leads to a progressive shift in the type of cells present at the site of inflammation and is characterized by simultaneous destruction and healing of the tissue from the inflammatory process. In many cases cancer is a direct effect of chronic inflammation (Li-Weber 2009). Inflammation orchestrates the microenvironment around 
tumors, contributing to proliferation, survival and migration. Baicalein has historically been applied as an herbal anti-inflammatory therapy in China (Li et al. 2006). When used as an agent against 7,12-dimethylbenz[a] anthracene (DMBA) / 12-O-tetradecanoylphorbol-13acetate (TPA)-mediated skin tumorigenesis, baicalein significantly inhibited the production of inflammatory cells, such as mast cells, macrophages, and neutrophils (Ma et al. 2013), all of which tend to assist in tumor growth and progression and are not effective sites to launch an attack against the tumor (Liu et al. 2010). In benzo(a)pyrene [B(a)P]-induced lung cancer bearing animals, administration of baicalein significantly counteracted B(a)P-induced increase of mature mase cell numbers and cytokines such as TNF- $\alpha$, interleukin-1 $\beta$, iNOS and NFkB (Chandrashekar et al. 2012). Baicalein were also found to inhibit the multifunctional cytokine Interleukin-6, suggesting it would serve as an anti-inflammatory treatment and provide a therapeutic effect on multiple myeloma patients (Liu et al. 2010). One of the possible anti-inflammatory mechanisms of baicalein is it reduces prostaglandin E2 (PGE2) release and arachidonic acid (AA) liberation through inhibiting MAPK-cytosolic phospholipase A2 (cPLA2) pathway (Nakahata et al. 1998).

\section{Bioavailability and improvement}

A lot of flavonoids display remarkable anti-cancer activity in cell models, however, it is still unknown how viable and readily available they work in human body. The upmost concern is poor bioavailability. Like other flavonoids, baicalein undergoes serious first-pass metabolism in intestine and liver in human and rats, which is responsible for its low bioavailability, predominantly in the form of glucuronidation, sulfation and methylation (Li et al. 2011b; Zhang et al. 2011b). UDP-glucuronosyltranferase (UGT) 1A9 demonstrated the fastest formation rate of baicalein in human liver preparations (Zhang et al. 2007). The efflux of conjugated metabolites which are produced intracellularly was mediated by membrane transporters, including multidrug resistance associated proteins (MRPs), breast cancer resistance protein (BCRP), human organic anion-transporting polypeptide (OATP) 2B1 and OATP1B3 (Zhang et al. 2011b). According to a Phase I, randomized, double-blind, singledose trial of baicalein carried out in 72 healthy adults ( $\mathrm{Li}$ et al. 2014), the maximum plasma concentration that the drug achieved after dosing (Cmax) ranged from 5.82 to $108.17 \mathrm{ng} / \mathrm{mL}$ after oral administration of 100-2800 mg baicalein.

To improve bioavailability of baicalein, one of the methods is to prepare it in the form of nanocrystal or with delivery systems. Baicalein nanocrystal showed rapid and extensive absorption. Its Cmax was much higher and half-life was much longer than free baicalein (Ts a i et al. 2012; Zhang et al. 2011a). Complexation with delivery systems could enhance the solubility and dissolution of baicalein (Huang et al. 2014; Liang et al. 2013; Liu et al. 2006; Liu et al. 2012; Zhang et al. 2014a). Delivery systems improved the pharmacokinetic properties of baicalein, leading to an increase in relative bioavailability. For example, when embedded with self-microemulsifying drug delivery system (SMEDDS), the drug release rate was significantly higher. The absorption of baicalein from SMEDDS resulted in about $200.7 \%$ increase in relative bioavailability than that of the baicalein suspension in rats by oral administration (Liu et al. 2012). 
Another way to solve this problem is to co-treat baicalein with compounds sharing the same metabolic pathways with baicalein, or UGT and SULT inhibitors. These compounds may interfere with the metabolism and absorption of baicalein. Acetaminophen, (-)-epicatechin, piperine and curcumin were proven to produce a dose-dependent inhibition on the glucuronidation and sulfation of baicalein (Fong et al. 2012). Among them, curcumin and high-dose (-)-epicatechin were demonstrated to subsequently increase the absorption of baicalein (Fong et al. 2012).

Modification of baicalein molecules to create analogs is also a strategy. Several baicalein derivatives were proven to have stronger cytotoxicity than baicalein. Baicalein derivatives, which were synthesized by introducing a group to $\mathrm{C6}-\mathrm{OH}$ and a nitrogen-containing hydrophilic heterocyclic ring to $\mathrm{C} 7-\mathrm{OH}$, exhibit more potent cytotoxicity than baicalein against HepG2, A549, and BCG-823 cancer cell lines (Luo et al. 2014). Baicalein derivatives with one geranyl group, baicalein sulfated derivatives, baicalein benzyl derivatives, and baicalein amino acid derivatives also showed a significant increase in cytotoxicity compared with baicalein (Ding et al. 2011; Li et al. 2013b; Neves et al. 2011; Wang et al. 2014a). Modified with O-alkylation and O-acylation, singly or in combination, on the ring A of baicalein evaluated the effects of their inhibitory activities against multidrug-resistant tumor cell lines and P-gp 170. Higher pro-oxidant property (Wang et al. 2014a), new target pathways (Ding et al. 2011) and more resistant to membrane transporters may be responsible for the enhanced anti-cancer efficacy of baicalein derivatives.

\section{Combination treatments}

Baicalein enhances the cytotoxicity and/or bioavailability of certain cancer therapy drugs. A synergistic therapeutic effect were observed when treated baicalein in combination with silymarin, vincristin or dexamethasone (Chen et al. 2009; Chen et al. 2013c; Otsuyama et al. 2007). In addition, baicalein was demonstrated to increase the cytotoxicity of cisplatin through enhancing gap junction intercellular communication (Wang et al. 2014b). Baicalein can increase the oral bioavailability of tamoxifen by inhibiting cytochrome P450 (CYP) 3A4-mediated metabolism of tamoxifen in the small intestine and/or liver, and Pglycoprotein (P-gp) efflux pump in the small intestine, reducting total body clearance in rats after an oral administration of baicalein and tamoxifen (Li et al. 2011a). Similarly, via inhibiting both P-gp and the CYP3A subfamily in the intestine and/or liver, the area under

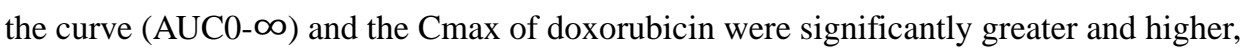
respectively in the presence of baicalein (Shin et al. 2009). The absolute and relative bioavailability of doxorubicin were also obviously increased compared with that of the control group (Shin et al. 2009).

\section{Conclusion}

Cancer proves to be one of greatest challenges in modern medicine. Present cancer treatments are usually with side effects and can be harmful to the healthy cells in the body. Baicalein, a flavonoid extract from the dried root of Scutellaria baicalensis Georgi, has the potential to decrease cancer growth and retard cancer promoting processes, such as angiogenesis, metastasis, and inflammation, without impairing normal cells. However, low 
bioavailability limits the application of baicalein. Improvement of baicalein bioavailability and combination treatment with other anti-cancer agents have shown some promise which could lead to a broader use of this flavonoid as a anti-cancer agent candidate. So far, most anti-cancer effects of baicalein have been observed in vitro or in animal models. In the future, more clinical trials should be carried out to investigate the anti-cancer activity of baicalein in human body and provide more evidence for its pharmacological use.

\section{Acknowledgments}

We thank Dr. Ross Brittain for his helpful suggestions on our manuscript. This material is based upon work supported by Dr. Yi Charlie Chen, Alderson Broaddus University, and the PUI/CTC Research Incubator Program funded by the National Science Foundation (NSF) under Grant Number EPS-1003907. As well as National Institutes of Health (NIH) grants P20RR016477 and P20GM103434.

\section{References}

Chandrashekar N, Selvamani A, Subramanian R, Pandi A, Thiruvengadam D. Baicalein inhibits pulmonary carcinogenesis-associated inflammation and interferes with COX-2, MMP-2 and MMP-9 expressions in-vivo. Toxicology and applied pharmacology. 2012; 261:10-21. [PubMed: 22369883]

Chao JI, Su WC, Liu HF. Baicalein induces cancer cell death and proliferation retardation by the inhibition of CDC2 kinase and survivin associated with opposite role of p38 mitogen-activated protein kinase and AKT. Molecular cancer therapeutics. 2007; 6:3039-3048. [PubMed: 18025287]

Chen AY, Chen YC. A review of the dietary flavonoid, kaempferol on human health and cancer chemoprevention. Food chemistry. 2013; 138:2099-2107. [PubMed: 23497863]

Chen CH, Huang LL, Huang CC, Lin CC, Lee Y, Lu FJ. Baicalein, a novel apoptotic agent for hepatoma cell lines: a potential medicine for hepatoma. Nutrition and cancer. 2000; 38:287-295. [PubMed: 11525608]

Chen CH, Huang TS, Wong CH, Hong CL, Tsai YH, Liang CC, Lu FJ, Chang WH. Synergistic anticancer effect of baicalein and silymarin on human hepatoma HepG2 Cells. Food and chemical toxicology : an international journal published for the British Industrial Biological Research Association. 2009; 47:638-644. [PubMed: 19150384]

Chen F, Zhuang M, Peng J, Wang X, Huang T, Li S, Lin M, Lin H, Xu Y, Li J, Chen Z, Huang Y. Baicalein inhibits migration and invasion of gastric cancer cells through suppression of the TGFbeta signaling pathway. Molecular medicine reports. 2014a; 10:1999-2003. [PubMed: 25109410]

Chen H, Gao Y, Wu J, Chen Y, Chen B, Hu J, Zhou J. Exploring therapeutic potentials of baicalin and its aglycone baicalein for hematological malignancies. Cancer letters. 2014b; 354:5-11. [PubMed: 25128647]

Chen J, Li Z, Chen AY, Ye X, Luo H, Rankin GO, Chen YC. Inhibitory effect of baicalin and baicalein on ovarian cancer cells. International journal of molecular sciences. 2013a; 14:6012-6025. [PubMed: 23502466]

Chen K, Zhang S, Ji Y, Li J, An P, Ren H, Liang R, Yang J, Li Z. Baicalein inhibits the invasion and metastatic capabilities of hepatocellular carcinoma cells via down-regulation of the ERK pathway. PloS one. 2013b; 8:e72927. [PubMed: 24039823]

Chen YJ, Wu CS, Shieh JJ, Wu JH, Chen HY, Chung TW, Chen YK, Lin CC. Baicalein Triggers Mitochondria-Mediated Apoptosis and Enhances the Antileukemic Effect of Vincristine in Childhood Acute Lymphoblastic Leukemia CCRF-CEM Cells. Evidence-based complementary and alternative medicine : eCAM. 2013c; 2013:124747. [PubMed: 23476680]

Cheng YH, Li LA, Lin P, Cheng LC, Hung CH, Chang NW, Lin C. Baicalein induces G1 arrest in oral cancer cells by enhancing the degradation of cyclin D1 and activating AhR to decrease Rb phosphorylation. Toxicology and applied pharmacology. 2012; 263:360-367. [PubMed: 22820424] 
Chiu YW, Lin TH, Huang WS, Teng CY, Liou YS, Kuo WH, Lin WL, Huang HI, Tung JN, Huang CY, Liu JY, Wang WH, Hwang JM, Kuo HC. Baicalein inhibits the migration and invasive properties of human hepatoma cells. Toxicology and applied pharmacology. 2011; 255:316-326. [PubMed: 21803068]

Cho H, Lee HY, Ahn DR, Kim SY, Kim S, Lee KB, Lee YM, Park H, Yang EG. Baicalein induces functional hypoxia-inducible factor-1alpha and angiogenesis. Molecular pharmacology. 2008; 74:70-81. [PubMed: 18426858]

Ding D, Zhang B, Meng T, Ma Y, Wang X, Peng H, Shen J. Novel synthetic baicalein derivatives caused apoptosis and activated AMP-activated protein kinase in human tumor cells. Organic \& biomolecular chemistry. 2011; 9:7287-7291. [PubMed: 21901221]

Fong YK, Li CR, Wo SK, Wang S, Zhou L, Zhang L, Lin G, Zuo Z. In vitro and in situ evaluation of herb-drug interactions during intestinal metabolism and absorption of baicalein. Journal of ethnopharmacology. 2012; 141:742-753. [PubMed: 21906668]

Gao J, Zhao H, Hylands PJ, Corcoran O. Secondary metabolite mapping identifies Scutellaria inhibitors of human lung cancer cells. Journal of pharmaceutical and biomedical analysis. 2010; 53:723-728. [PubMed: 20457505]

Hemmings BA, Restuccia DF. PI3K-PKB/Akt pathway. Cold Spring Harbor perspectives in biology. 2012; 4:a011189. [PubMed: 22952397]

Huang Y, Zhang B, Gao Y, Zhang J, Shi L. Baicalein-nicotinamide cocrystal with enhanced solubility, dissolution, and oral bioavailability. Journal of pharmaceutical sciences. 2014; 103:2330-2337. [PubMed: 24903146]

Hwang KY, Oh YT, Yoon H, Lee J, Kim H, Choe W, Kang I. Baicalein suppresses hypoxia-induced HIF-1alpha protein accumulation and activation through inhibition of reactive oxygen species and PI 3-kinase/Akt pathway in BV2 murine microglial cells. Neuroscience letters. 2008; 444:264 269. [PubMed: 18771709]

Kasibhatla S, Tseng B. Why target apoptosis in cancer treatment? Molecular cancer therapeutics. 2003; 2:573-580. [PubMed: 12813137]

Kim DH, Hossain MA, Kang YJ, Jang JY, Lee YJ, Im E, Yoon JH, Kim HS, Chung HY, Kim ND. Baicalein, an active component of Scutellaria baicalensis Georgi, induces apoptosis in human colon cancer cells and prevents AOM/DSS-induced colon cancer in mice. International journal of oncology. 2013; 43:1652-1658. [PubMed: 24008356]

Kim SJ, Kim HJ, Kim HR, Lee SH, Cho SD, Choi CS, Nam JS, Jung JY. Antitumor actions of baicalein and wogonin in HT-29 human colorectal cancer cells. Molecular medicine reports. 2012; 6:1443-1449. [PubMed: 22992837]

Kong D, Zhang Y, Yamori T, Duan H, Jin M. Inhibitory activity of flavonoids against class I phosphatidylinositol 3-kinase isoforms. Molecules. 2011; 16:5159-5167. [PubMed: 21694679]

Lee HZ, Leung HW, Lai MY, Wu CH. Baicalein induced cell cycle arrest and apoptosis in human lung squamous carcinoma CH27 cells. Anticancer research. 2005; 25:959-964. [PubMed: 15868934]

Lee IK, Kang KA, Zhang R, Kim BJ, Kang SS, Hyun JW. Mitochondria protection of baicalein against oxidative damage via induction of manganese superoxide dismutase. Environmental toxicology and pharmacology. 2011; 31:233-241. [PubMed: 21787690]

Lee JH, Li YC, Ip SW, Hsu SC, Chang NW, Tang NY, Yu CS, Chou ST, Lin SS, Lino CC, Yang JS, Chung JG. The role of $\mathrm{Ca} 2+$ in baicalein-induced apoptosis in human breast MDA-MB-231 cancer cells through mitochondria- and caspase-3-dependent pathway. Anticancer research. 2008; 28:1701-1711. [PubMed: 18630529]

Leung HW, Yang WH, Lai MY, Lin CJ, Lee HZ. Inhibition of 12-lipoxygenase during baicaleininduced human lung nonsmall carcinoma H460 cell apoptosis. Food and chemical toxicology : an international journal published for the British Industrial Biological Research Association. 2007; 45:403-411. [PubMed: 17050058]

Li-Weber M. New therapeutic aspects of flavones: the anticancer properties of Scutellaria and its main active constituents Wogonin, Baicalein and Baicalin. Cancer treatment reviews. 2009; 35:57-68. [PubMed: 19004559]

Li C, Kim M, Choi H, Choi J. Effects of baicalein on the pharmacokinetics of tamoxifen and its main metabolite, 4-hydroxytamoxifen, in rats: possible role of cytochrome P450 3A4 and P- 
glycoprotein inhibition by baicalein. Archives of pharmacal research. 2011a; 34:1965-1972. [PubMed: 22139696]

Li C, Lin G, Zuo Z. Pharmacological effects and pharmacokinetics properties of Radix Scutellariae and its bioactive flavones. Biopharmaceutics \& drug disposition. 2011b; 32:427-445. [PubMed: 21928297]

Li HL, Zhang S, Wang Y, Liang RR, Li J, An P, Wang ZM, Yang J, Li ZF. Baicalein induces apoptosis via a mitochondrial-dependent caspase activation pathway in T24 bladder cancer cells. Molecular medicine reports. 2013a; 7:266-270. [PubMed: 23064738]

Li L, Liu WY, Feng F, Wu CY, Xie N. Synthesis and in vitro cytotoxicity evaluation of baicalein amino acid derivatives. Chinese journal of natural medicines. 2013b; 11:284-288. [PubMed: 23725843]

Li M, Shi A, Pang H, Xue W, Li Y, Cao G, Yan B, Dong F, Li K, Xiao W, He G, Du G, Hu X. Safety, tolerability, and pharmacokinetics of a single ascending dose of baicalein chewable tablets in healthy subjects. Journal of ethnopharmacology. 2014; 156:210-215. [PubMed: 25219601]

Li QB, You Y, Chen ZC, Lu J, Shao J, Zou P. Role of Baicalein in the regulation of proliferation and apoptosis in human myeloma RPMI8226 cells. Chinese medical journal. 2006; 119:948-952. [PubMed: 16780776]

Liang J, Wu W, Liu Q, Chen S. Long-circulating nanoliposomes (LCNs) sustained delivery of baicalein (BAI) with desired oral bioavailability in vivo. Drug delivery. 2013; 20:319-323. [PubMed: 24028326]

Lin MG, Liu LP, Li CY, Zhang M, Chen Y, Qin J, Gu YY, Li Z, Wu XL, Mo SL. Scutellaria extract decreases the proportion of side population cells in a myeloma cell line by down-regulating the expression of ABCG2 protein. Asian Pacific journal of cancer prevention : APJCP. 2013; 14:71797186. [PubMed: 24460272]

Lin YT, Yang JS, Lin HJ, Tan TW, Tang NY, Chaing JH, Chang YH, Lu HF, Chung JG. Baicalein induces apoptosis in SCC-4 human tongue cancer cells via a Ca2+-dependent mitochondrial pathway. In vivo. 2007; 21:1053-1058. [PubMed: 18210755]

Ling Y, Chen Y, Chen P, Hui H, Song X, Lu Z, Li C, Lu N, Guo Q. Baicalein potently suppresses angiogenesis induced by vascular endothelial growth factor through the $\mathrm{p} 53 / \mathrm{Rb}$ signaling pathway leading to G1/S cell cycle arrest. Experimental biology and medicine. 2011; 236:851-858. [PubMed: 21659383]

Liu J, Qiu L, Gao J, Jin Y. Preparation, characterization and in vivo evaluation of formulation of baicalein with hydroxypropyl-beta-cyclodextrin. International journal of pharmaceutics. 2006; 312:137-143. [PubMed: 16459034]

Liu JJ, Huang TS, Cheng WF, Lu FJ. Baicalein and baicalin are potent inhibitors of angiogenesis: Inhibition of endothelial cell proliferation, migration and differentiation. International journal of cancer Journal international du cancer. 2003; 106:559-565. [PubMed: 12845652]

Liu S, Ma Z, Cai H, Li Q, Rong W, Kawano M. Inhibitory effect of baicalein on IL-6-mediated signaling cascades in human myeloma cells. European journal of haematology. 2010; 84:137-144. [PubMed: 19878271]

Liu TY, Gong W, Tan ZJ, Lu W, Wu XS, Weng H, Ding Q, Shu YJ, Bao RF, Cao Y, Wang XA, Zhang F, Li HF, Xiang SS, Jiang L, Hu YP, Mu JS, Li ML, Wu WG, Shen BY, Jiang LX, Liu YB.

Baicalein inhibits progression of gallbladder cancer cells by downregulating ZFX. PloS one. 2015; 10:e0114851. [PubMed: 25617627]

Liu W, Tian R, Hu W, Jia Y, Jiang H, Zhang J, Zhang L. Preparation and evaluation of selfmicroemulsifying drug delivery system of baicalein. Fitoterapia. 2012; 83:1532-1539. [PubMed: 22982454]

Luo R, Wang J, Zhao L, Lu N, You Q, Guo Q, Li Z. Synthesis and biological evaluation of baicalein derivatives as potent antitumor agents. Bioorganic \& medicinal chemistry letters. 2014; 24:13341338. [PubMed: 24507925]

Ma GZ, Liu CH, Wei B, Qiao J, Lu T, Wei HC, Chen HD, He CD. Baicalein inhibits DMBA/TPAinduced skin tumorigenesis in mice by modulating proliferation, apoptosis, and inflammation. Inflammation. 2013; 36:457-467. [PubMed: 23108957] 
Mehendale S, Aung H, Wang CZ, Tong R, Foo A, Xie JT, Yuan CS. Scutellaria baicalensis and a constituent flavonoid, baicalein, attenuate ritonavir-induced gastrointestinal side-effects. The Journal of pharmacy and pharmacology. 2007; 59:1567-1572. [PubMed: 17976269]

Miocinovic R, McCabe NP, Keck RW, Jankun J, Hampton JA, Selman SH. In vivo and in vitro effect of baicalein on human prostate cancer cells. International journal of oncology. 2005; 26:241-246. [PubMed: 15586246]

Moon YJ, Wang X, Morris ME. Dietary flavonoids: effects on xenobiotic and carcinogen metabolism. Toxicology in vitro : an international journal published in association with BIBRA. 2006; 20:187210. [PubMed: 16289744]

Nakahata N, Kutsuwa M, Kyo R, Kubo M, Hayashi K, Ohizumi Y. Analysis of inhibitory effects of scutellariae radix and baicalein on prostaglandin $\mathrm{E} 2$ production in rat $\mathrm{C} 6$ glioma cells. The American journal of Chinese medicine. 1998; 26:311-323. [PubMed: 9862019]

Neves MP, Cidade H, Pinto M, Silva AM, Gales L, Damas AM, Lima RT, Vasconcelos MH, de Sao Jose Nascimento M. Prenylated derivatives of baicalein and 3,7-dihydroxyflavone: synthesis and study of their effects on tumor cell lines growth, cell cycle and apoptosis. European journal of medicinal chemistry. 2011; 46:2562-2574. [PubMed: 21496973]

Otsuyama KI, Ma Z, Abroun S, Amin J, Shamsasenjan K, Asaoku H, Kawano MM. PPARbetamediated growth suppression of baicalein and dexamethasone in human myeloma cells. Leukemia. 2007; 21:187-190. [PubMed: 17082776]

Pelicano H, Carney D, Huang P. ROS stress in cancer cells and therapeutic implications. Drug resistance updates : reviews and commentaries in antimicrobial and anticancer chemotherapy. 2004; 7:97-110. [PubMed: 15158766]

Pidgeon GP, Kandouz M, Meram A, Honn KV. Mechanisms controlling cell cycle arrest and induction of apoptosis after 12-lipoxygenase inhibition in prostate cancer cells. Cancer research. 2002; 62:2721-2727. [PubMed: 11980674]

Po LS, Chen ZY, Tsang DS, Leung LK. Baicalein and genistein display differential actions on estrogen receptor (ER) transactivation and apoptosis in MCF-7 cells. Cancer letters. 2002; 187:33-40. [PubMed: 12359348]

Shang D, Li Z, Zhu Z, Chen H, Zhao L, Wang X, Chen Y. Baicalein suppresses 17-beta-estradiolinduced migration, adhesion and invasion of breast cancer cells via the $G$ protein-coupled receptor 30 signaling pathway. Oncology reports. 2015; 33:2077-2085. [PubMed: 25672442]

Shin SC, Li C, Choi JS. Effects of baicalein, an antioxidant, on the bioavailability of doxorubicin in rats: possible role of P-glycoprotein inhibition by baicalein. Die Pharmazie. 2009; 64:579-583. [PubMed: 19827298]

Sithranga Boopathy N, Kathiresan K. Anticancer drugs from marine flora: an overview. Journal of oncology. 2010; 2010:214186. [PubMed: 21461373]

Tang Z, Li C, Chen Z. [Inhibitory effect of baicalein on the proliferation and invasion of osteosarcoma cells and mechanism]. Xi bao yu fen zi mian yi xue za zhi $=$ Chinese journal of cellular and molecular immunology. 2015; 31:342-345. [PubMed: 25744840]

Taniguchi H, Yoshida T, Horinaka M, Yasuda T, Goda AE, Konishi M, Wakada M, Kataoka K, Yoshikawa T, Sakai T. Baicalein overcomes tumor necrosis factor-related apoptosis-inducing ligand resistance via two different cell-specific pathways in cancer cells but not in normal cells. Cancer research. 2008; 68:8918-8927. [PubMed: 18974136]

Tong WG, Ding XZ, Adrian TE. The mechanisms of lipoxygenase inhibitor-induced apoptosis in human breast cancer cells. Biochemical and biophysical research communications. 2002a; 296:942-948. [PubMed: 12200139]

Tong WG, Ding XZ, Witt RC, Adrian TE. Lipoxygenase inhibitors attenuate growth of human pancreatic cancer xenografts and induce apoptosis through the mitochondrial pathway. Molecular cancer therapeutics. 2002b; 1:929-935. [PubMed: 12481414]

Tsai MJ, Wu PC, Huang YB, Chang JS, Lin CL, Tsai YH, Fang JY. Baicalein loaded in tocol nanostructured lipid carriers (tocol NLCs) for enhanced stability and brain targeting. International journal of pharmaceutics. 2012; 423:461-470. [PubMed: 22193056]

Tyagi AK, Singh RP, Agarwal C, Chan DC, Agarwal R. Silibinin strongly synergizes human prostate carcinoma DU145 cells to doxorubicin-induced growth Inhibition, G2-M arrest, and apoptosis. 
Clinical cancer research : an official journal of the American Association for Cancer Research. 2002; 8:3512-3519. [PubMed: 12429642]

Wang CZ, Li XL, Wang QF, Mehendale SR, Yuan CS. Selective fraction of Scutellaria baicalensis and its chemopreventive effects on MCF-7 human breast cancer cells. Phytomedicine : international journal of phytotherapy and phytopharmacology. 2010a; 17:63-68. [PubMed: 19836937]

Wang J, Yi J. Cancer cell killing via ROS: to increase or decrease, that is the question. Cancer biology \& therapy. 2008; 7:1875-1884. [PubMed: 18981733]

Wang L, Ling Y, Chen Y, Li CL, Feng F, You QD, Lu N, Guo QL. Flavonoid baicalein suppresses adhesion, migration and invasion of MDA-MB-231 human breast cancer cells. Cancer letters. 2010b; 297:42-48. [PubMed: 20580866]

Wang N, Ren D, Deng S, Yang X. Differential effects of baicalein and its sulfated derivatives in inhibiting proliferation of human breast cancer MCF-7 cells. Chemico-biological interactions. 2014a; 221:99-108. [PubMed: 25130856]

Wang Y, Wang Q, Zhang S, Zhang Y, Tao L. Baicalein increases the cytotoxicity of cisplatin by enhancing gap junction intercellular communication. Molecular medicine reports. 2014b; 10:515521. [PubMed: 24736991]

Wong RS. Apoptosis in cancer: from pathogenesis to treatment. Journal of experimental \& clinical cancer research : CR. 2011; 30:87. [PubMed: 21943236]

Wu B, Li J, Huang D, Wang W, Chen Y, Liao Y, Tang X, Xie H, Tang F. Baicalein mediates inhibition of migration and invasiveness of skin carcinoma through Ezrin in A431 cells. BMC cancer. 2011; 11:527. [PubMed: 22204275]

Wu JY, Tsai KW, Li YZ, Chang YS, Lai YC, Laio YH, Wu JD, Liu YW. Anti-Bladder-Tumor Effect of Baicalein from Scutellaria baicalensis Georgi and Its Application In Vivo. Evidence-based complementary and alternative medicine : eCAM. 2013; 2013:579751. [PubMed: 23573134]

Yan X, Rui X, Zhang K. Baicalein inhibits the invasion of gastric cancer cells by suppressing the activity of the p38 signaling pathway. Oncology reports. 2015; 33:737-743. [PubMed: 25502212]

Ye F, Wang H, Zhang L, Zou Y, Han H, Huang J. Baicalein induces human osteosarcoma cell line MG-63 apoptosis via ROS-induced BNIP3 expression. Tumour biology : the journal of the International Society for Oncodevelopmental Biology and Medicine. 2015

Zhang HB, Lu P, Guo QY, Zhang ZH, Meng XY. Baicalein induces apoptosis in esophageal squamous cell carcinoma cells through modulation of the PI3K/Akt pathway. Oncology letters. 2013a; 5:722-728. [PubMed: 23420294]

Zhang J, Lv H, Jiang K, Gao Y. Enhanced bioavailability after oral and pulmonary administration of baicalein nanocrystal. International journal of pharmaceutics. 2011a; 420:180-188. [PubMed: 21878378]

Zhang L, Li C, Lin G, Krajcsi P, Zuo Z. Hepatic metabolism and disposition of baicalein via the coupling of conjugation enzymes and transporters-in vitro and in vivo evidences. The AAPS journal. 2011b; 13:378-389. [PubMed: 21607811]

Zhang L, Lin G, Zuo Z. Involvement of UDP-glucuronosyltransferases in the extensive liver and intestinal first-pass metabolism of flavonoid baicalein. Pharmaceutical research. 2007; 24:81-89. [PubMed: 17109214]

Zhang Y, Luo R, Chen Y, Ke X, Hu D, Han M. Application of carrier and plasticizer to improve the dissolution and bioavailability of poorly water-soluble baicalein by hot melt extrusion. AAPS PharmSciTech. 2014a; 15:560-568. [PubMed: 24570374]

Zhang Y, Song L, Cai L, Wei R, Hu H, Jin W. Effects of baicalein on apoptosis, cell cycle arrest, migration and invasion of osteosarcoma cells. Food and chemical toxicology : an international journal published for the British Industrial Biological Research Association. 2013b; 53:325-333. [PubMed: 23266503]

Zhang Z, Lv J, Lei X, Li S, Zhang Y, Meng L, Xue R, Li Z. Baicalein reduces the invasion of glioma cells via reducing the activity of p38 signaling pathway. PloS one. 2014b; 9:e90318. [PubMed: 24587321]

Zhou QM, Wang S, Zhang H, Lu YY, Wang XF, Motoo Y, Su SB. The combination of baicalin and baicalein enhances apoptosis via the ERK/p38 MAPK pathway in human breast cancer cells. Acta pharmacologica Sinica. 2009; 30:1648-1658. [PubMed: 19960010] 


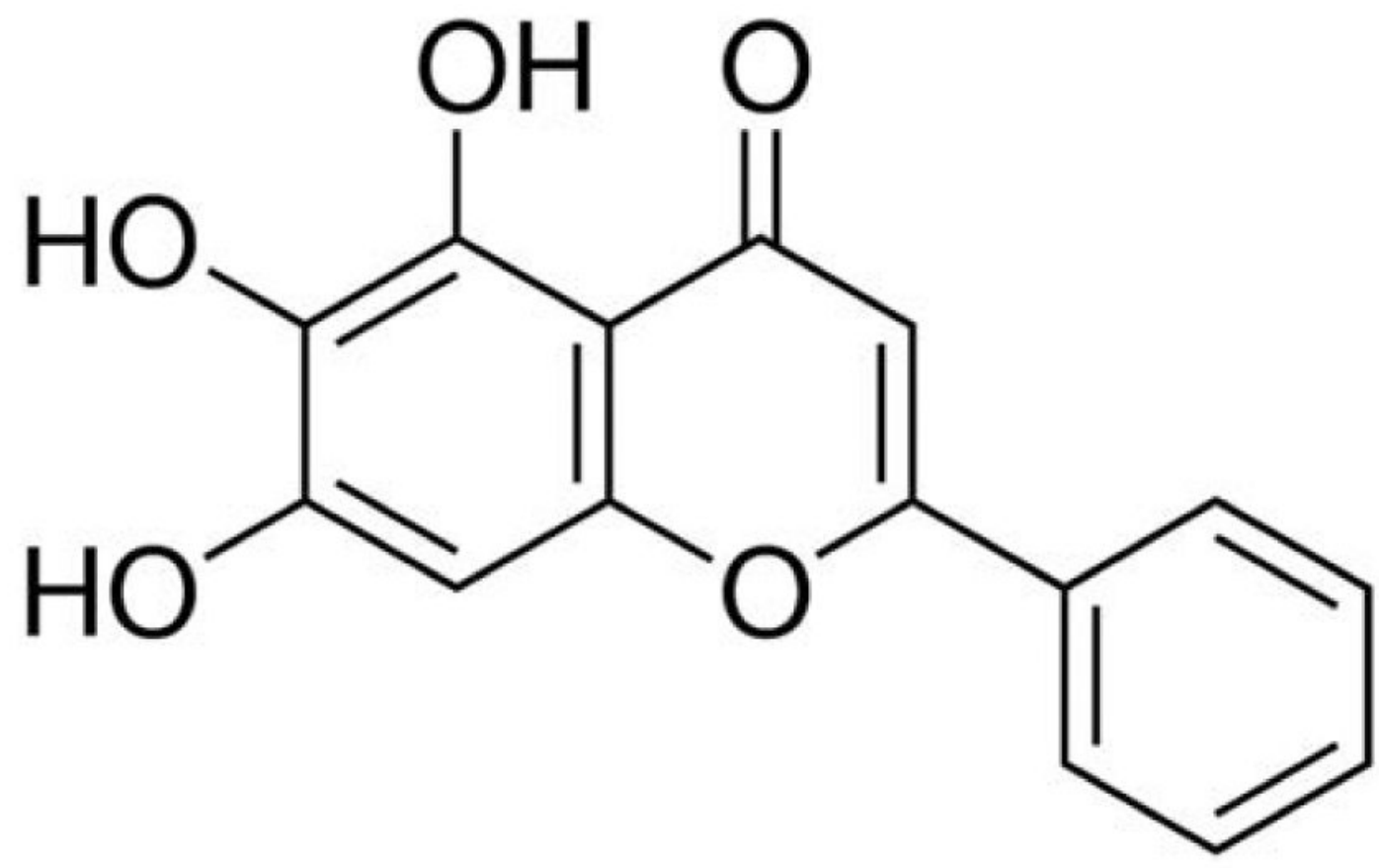

Fig. 1. Chemical structure of baicalein

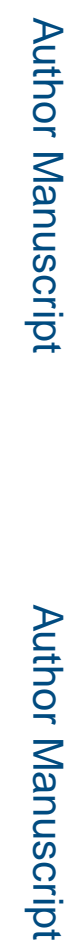




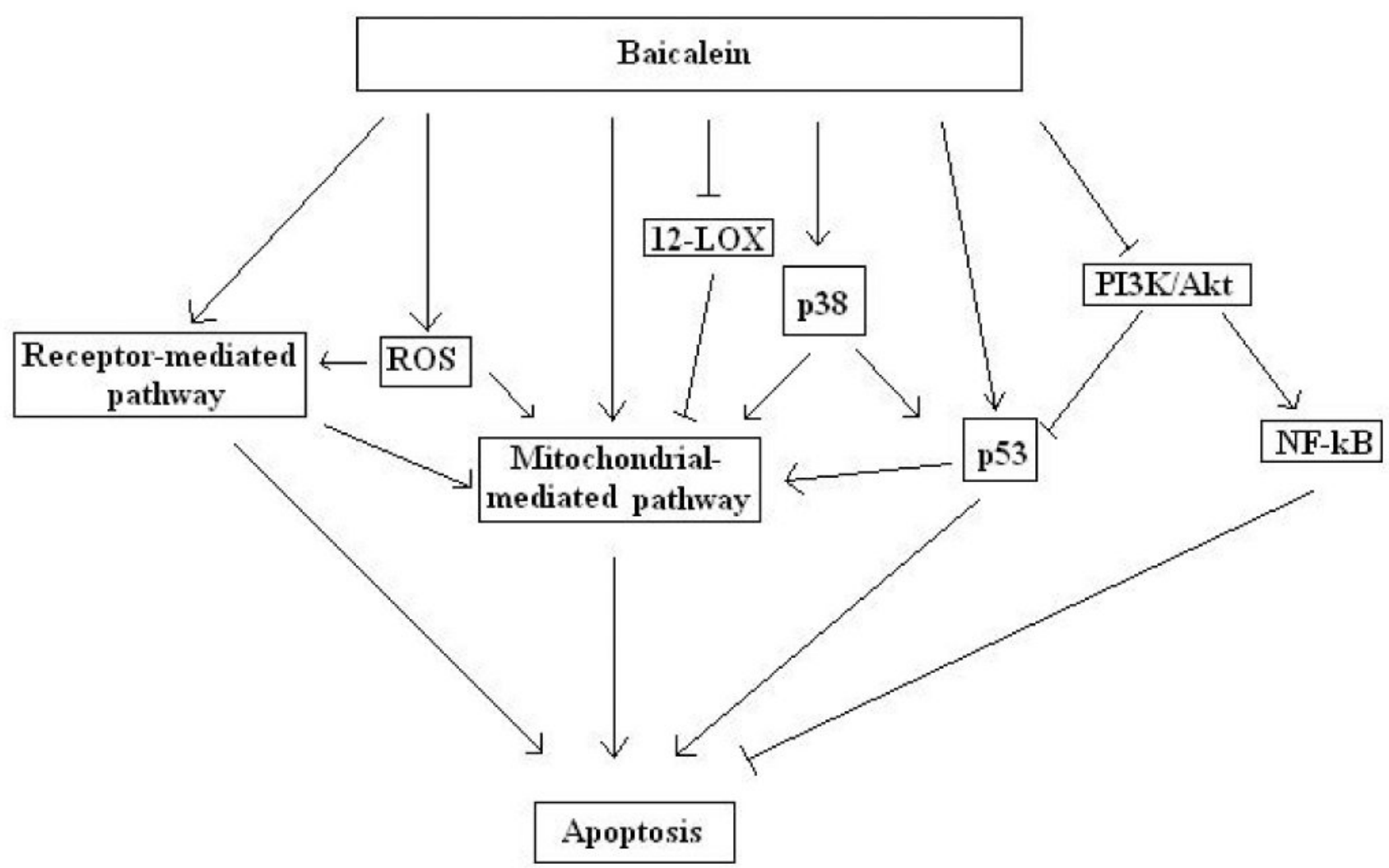

Fig. 2.

Baicalein induced apoptosis in cancer cells through multiple mechanisms, such as increasing reactive oxygen species (ROS) level, inactivating 12-Lipoxygenase (12-LOX), inhibiting $\mathrm{PI} 3 \mathrm{~K} / \mathrm{Akt}$ and its down-stream proteins, as well as up-regulating tumor suppressors p38 and p53. 


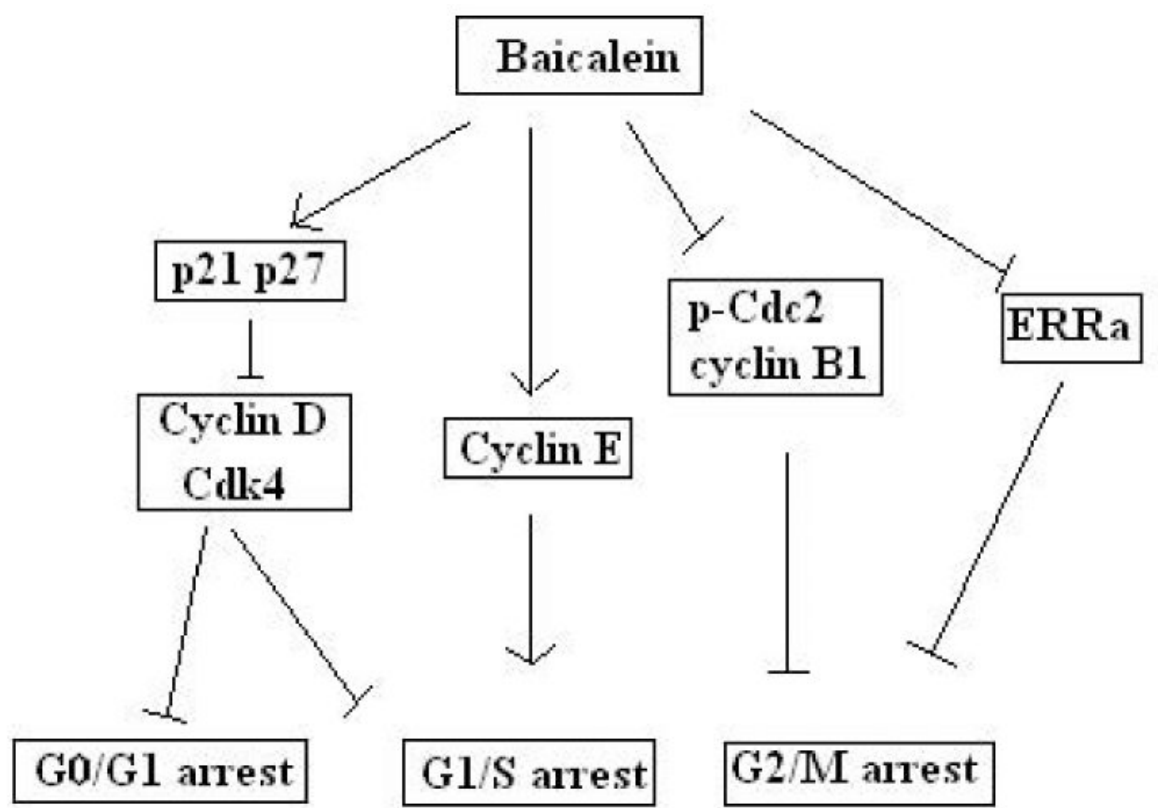

Fig. 3. Baicalein induced cell cycle arrest in cancer cells mainly via inhibiting cyclin-dependent kinases (CDKs) and cyclins, and up-regulating CDK inhibitors (CDKIs) 


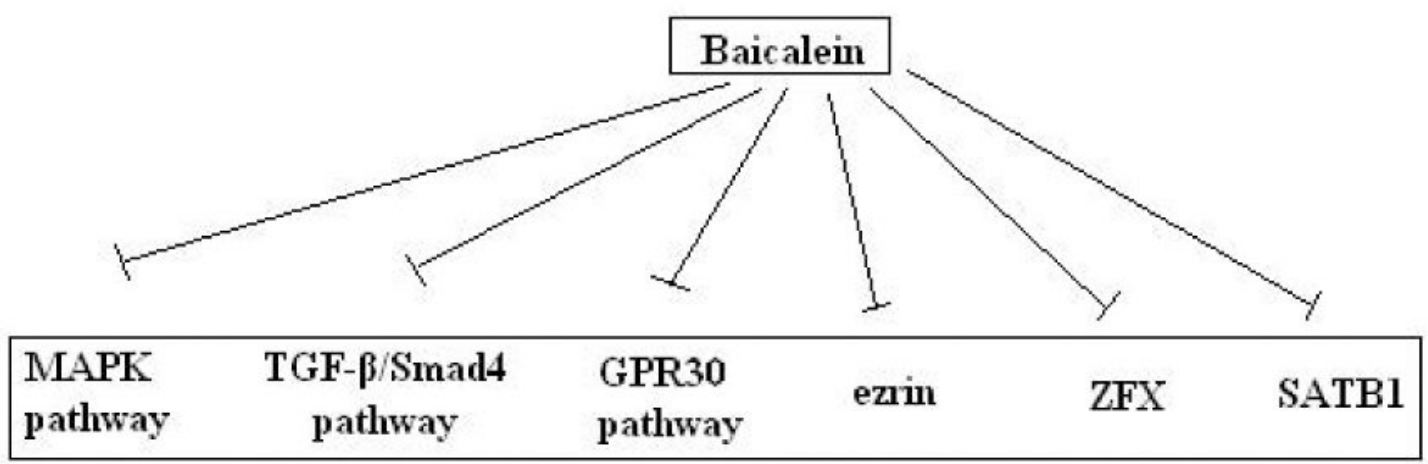

metastasis

Fig. 4.

Baicalein reduced metastasis of cancer cells by targeting the MAPK pathway, TGF- $\beta$ / Smad4 pathway, GPR30 pathway, ezrin, Zinc finger protein X-linked (ZFX) or special adenine-thymine (AT)-rich DNA-binding protein 1 (SATB1). 

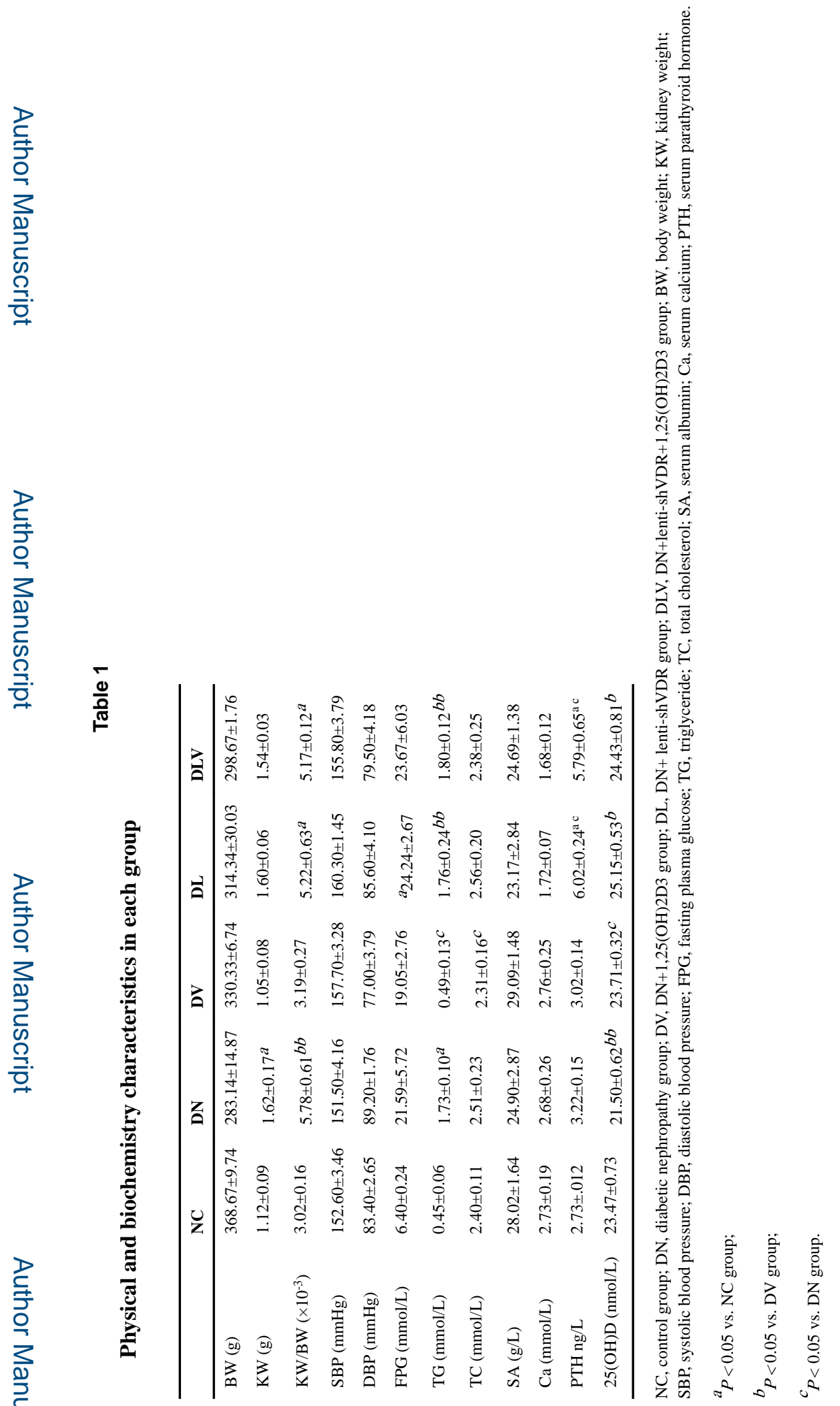